\title{
Influence of the frequency of pulsating high-pressure cutting fluid jets on the resulting chip length and surface finish
}

\author{
Antonia Splettstoesser $^{1} \cdot$ Daniel Schraknepper ${ }^{1} \cdot$ Thomas Bergs $^{1,2}$ \\ Received: 4 January 2021 / Accepted: 28 April 2021 / Published online: 17 May 2021 \\ (C) The Author(s) 2021
}

\begin{abstract}
High-pressure cutting fluid supply is a proven technology for chip breaking when turning difficult-to-cut materials, such as Inconel 718. However, the technology is usually not suitable for the finish turning of safety-critical parts in aero engines. The acting force of the cutting fluid jet on the back of the chip causes chip breaking. The broken chips are then accelerated by the cutting fluid jet towards the workpiece surfaces where they cause damage on impact. One approach to minimize surface damage is a specific increase in the chip length. The center of gravity of the chips with an adjusted length is shifted out of the focus where the cutting fluid jet hits the chips. Hence, the already finished surface is subjected to fewer impacts of the chips. In this study, the adjustment of the chip length by pulsating high-pressure cutting fluid supply to prevent surface damage was investigated. A valve unit was used to generate two alternating cutting fluid supply pressure levels in certain time intervals. During the low-pressure stage, the force of the cutting fluid jet does not lead to chip breakage and the chip length increases until the valves switch and the high-pressure stage is released. The focus of this work was the analysis of the relationship between the duration of the lowpressure and high-pressure time intervals and the chip length. Additionally, the influence of the depth of cut, the feed, and the cutting speed on the chip length during pulsating high-pressure cutting fluid supply was investigated. Finally, a case study was carried out to evaluate the effectiveness of the pulsating high-pressure cutting fluid supply technology. Therefore, the shoulder surface of a demonstrator part was finished by face turning. Following, the cylindrical surface was finished with a continuous and pulsating high-pressure cutting fluid supply with varied supply parameters. Microscopic analyses of the surface prove that the pulsating high-pressure cutting fluid supply prevents the surface from being damaged by the impacts of chips.
\end{abstract}

Keywords Chip control $\cdot$ High-pressure $\cdot$ Cutting fluid supply $\cdot$ HPJAM $\cdot$ Turning $\cdot$ Inconel 718

\section{Introduction}

Components in aero engines have to withstand high temperatures and extensive mechanical loads, especially when they are located in areas exposed to high temperatures, such as the combustion chamber of gas turbine engines. At the same time, the components must be extremely reliable, as failure can lead to damage to the entire engine. To meet these

Antonia Splettstoesser

a.splettstoesser@wzl.rwth-aachen.de

1 Laboratory for Machine Tools and Production Engineering WZL of RWTH Aachen University, Campus-Boulevard 30,

52074 Aachen, Germany

2 Fraunhofer Institute for Production Technology IPT, Steinbachstr. 17, 52074 Aachen, Germany requirements, the parts must be manufactured from materials with excellent corrosion resistance and high-temperature strength, such as nickel-based superalloys [1]. The most frequently used nickel-based superalloy in this area is Inconel 718 [2]. During the turning of Inconel 718, different challenges appear. Therefore, it is classified as a difficult-to-cut material. On the one hand, its low thermal conductivity results in high temperatures in the cutting zone. Additionally, high cutting forces arise, the material causes abrasive tool wear, and work hardening effects occur. As a result, the applicable cutting parameters, in particular the feed and the cutting speed, are very limited and the processes have low productivity. An increase in the cutting parameters will lead to excessive tool wear [3]. On the other hand, long helical chips occur when turning Inconel 718 [4]. These chips tend to wrap themselves around the chuck, and the workpiece and the tool and can damage them in the 
process. Additionally, manual chip removal is required which leads to downtimes and difficulties in automated production [5].

The productivity and process reliability in the rough turning of difficult-to-cut materials are often increased by the use of high-pressure (HP) cutting fluid (CF) supply [6]. Therefore, one or more $\mathrm{CF}$ jets are aimed directly in the cutting zone with high supply pressures of $p \geq 80$ bar [7]. When the jet is focused on the rake face of the tool, a fluid wedge between the rake face and the forming chip is built [8]. As a result, an increased cooling and lubrication effect in comparison to conventional flood cooling is achieved [7]. Therefore, a reduction of the temperature of the tool and increased tool lifetimes are obtained [9]. Additionally, the acting force of the CF jet causes a reduction of the chip curling radius [8]. This results in chip breakage [9]. However, the ecological and economic potential of the HP CF supply technology cannot be exploited in finish turning of safety-critical parts like turbine discs, yet. The acting force of the CF jet breaks the chips and accelerates them towards workpiece surfaces where they cause damage on impact $[10,11]$. The resulting surface damages have a negative effect on the lifetime of the produced parts $[12,13]$.

One approach to minimize the surface damage is a specific increase in the chip length [11]. The center of gravity of a chip with an adjusted length is shifted out of the focus where the CF jet hits the chips. Hence, the already finished surface is subjected to fewer impacts of the chips. Furthermore, only a small part of the kinetic energy of a long chip will be transferred into the workpiece surface on impact, because it is mainly absorbed by its elastic-plastic deformation. Consequently, no or less severe damage occurs on the workpiece surface. The adaption of the resulting chip length can be realized by the use of a pulsating HP CF supply technology. Therefore, the CF is supplied in two alternating pressure stages. During the low-pressure stage, the acting force of the CF jet does not lead to chip breakage. The chip length increases until the short HP stage begins and the chip is broken by the impact of the CF jet [14]. The focus of this work was the analysis of the relationship between the duration of the low-pressure and HP time intervals and the chip length. Additionally, the influence of the depth of cut, the feed, and the cutting speed on the chip length during pulsating HP cutting fluid supply was investigated. Finally, a case study was carried out to evaluate the effectiveness of the pulsating HP cutting fluid supply technology. Therefore, the shoulder surface of a demonstrator part was finished by face turning. Following, the cylindrical surface was finished with continuous and pulsating HP cutting fluid supply with varied supply parameters. Microscopic analyses of the finished face prove that the pulsating HP cutting fluid supply prevents the surface from being damaged by the impacts of chips.

\section{State of the art}

After Pigott and Colwell first elaborated that the use of HP CF supply leads to increased tool lifetimes in turning processes [15], numerous research works about this technology were carried out. They are related to various difficult-to-cut materials, like nickel-based or titanium alloys or high-strength steels. Furthermore, different cutting tool materials were analysed. In the following, the most relevant research results concerning chip control during turning of Inconel 718 with carbide inserts under HP CF supply are described.

Ezugwu and Bonney reported effective chip segmentation due to HP CF supply for different cutting conditions $[4,16]$. The chip form was influenced to a greater extent by the coolant supply pressure than by the cutting conditions [4]. When turning Inconel 718 under roughing conditions, with a depth of cut between $2.5 \mathrm{~mm} \leq a_{\mathrm{p}} \leq 3.0 \mathrm{~mm}$, cutting speeds in a range of $20 \mathrm{~m} / \mathrm{min} \leq v_{\mathrm{c}} \leq 50 \mathrm{~m} / \mathrm{min}$ and feeds between $0.25 \mathrm{~mm} \leq f \leq 0.3 \mathrm{~mm}$, long helical chips occurred for CF supply pressures up to $p_{\mathrm{CF}}=150 \mathrm{bar}$. At a CF supply pressure of $p_{\mathrm{CF}}=203$ bar, small chip segments resulted. Further experiments were conducted under finishing conditions, with a depth of cut of $a_{\mathrm{p}}=0.5 \mathrm{~mm}$, cutting speeds between $30 \mathrm{~m} /$ $\min \leq v_{\mathrm{c}} \leq 60 \mathrm{~m} / \mathrm{min}$ and feeds between $0.1 \mathrm{~mm} \leq f \leq 0.2 \mathrm{~mm}$ [16]. When conventional flood cooling was applied, long helical chips occurred. High CF supply pressures up to $p_{\mathrm{CF}} \leq$ 150 bar led to short helical chips. At a supply pressure of $p_{\mathrm{CF}}=$ 203 bar, small c-shaped chips were achieved.

Sharman et al. carried out turning experiments with a cutting speed of $v_{\mathrm{c}}=40 \mathrm{~m} / \mathrm{min}$, a feed of $f=0.35 \mathrm{~mm}$, and a depth of cut of $a_{p}=0.25 \mathrm{~mm}$ [17]. During conventional flood cooling and at a CF supply pressure of $p_{\mathrm{CF}}=70$ bar, long continuous helical chips occurred. At a CF supply pressure of $=150$ bar through a nozzle with a diameter $D=1 \mathrm{~mm}$, short helical chips occurred and small $\mathrm{c}$-shape chips were formed during turning with $\mathrm{CF}$ supply pressures $p_{\mathrm{CF}}=300$ bar and $p_{\mathrm{CF}}=$ 450 bar.

Courbon et al. analysed the machining performance during turning of Inconel 718 with HP CF supply using a nozzle with a diameter $D=0.25 \mathrm{~mm}$ [18]. The chip form was reported for a feed $f=0.25 \mathrm{~mm}$ and a depth of cut $\mathrm{a}_{\mathrm{p}}=2 \mathrm{~mm}$. At a CF supply pressure of $p_{\mathrm{CF}}=500 \mathrm{bar}$ and a cutting speed of $v_{\mathrm{c}}=63$ $\mathrm{m} / \mathrm{min}$, short helical chips occurred. When increasing the cutting speed to $v_{\mathrm{c}}=81 \mathrm{~m} / \mathrm{min}$, the chip length decreased and at a cutting speed $v_{\mathrm{c}}=127 \mathrm{~m} / \mathrm{min}$ only cylindrical helical chips resulted. Furthermore, experiments with an increased supply pressure $p_{\mathrm{CF}}=1300$ bar were carried out. At the lowest cutting speed $v_{\mathrm{c}}=63 \mathrm{~m} / \mathrm{min}$, short helical chips and cylindrical helical chips occurred. At a cutting speed $v_{\mathrm{c}}=81 \mathrm{~m} / \mathrm{min}$, exclusively cylindrical helical chips resulted. At the highest investigated cutting speed $v_{\mathrm{c}}=127 \mathrm{~m} / \mathrm{min}$, small c-shaped chip segments with a decreased upcurl radius were detected. Thus, the effect 
of the HP CF supply was enforced by an increased cutting speed. This was also shown for the feed.

Klocke et al. conducted turning experiments with a cutting speed $v_{\mathrm{c}}=60 \mathrm{~m} / \mathrm{min}$, a depth of cut $a_{\mathrm{p}}=1.0 \mathrm{~mm}$, and a feed $f$ $=0.2 \mathrm{~mm}[19]$. Three nozzles, each with a diameter of $D=$ $0.75 \mathrm{~mm}$, were applied. At a CF supply pressure $p_{\mathrm{CF}}=300$ bar, small c-shaped chips resulted.

The focus of more recent research was mostly on the development of tool wear. Nevertheless, the improved chip breakage due to the application of HP CF supply was also repeatedly demonstrated [20-23].

In conclusion, recent research work showed that the HP CF supply strategy is a well-suited technology to cause chip breakage during turning of Inconel 718 with coated carbide tools. The required CF supply pressure depends on the cutting parameters and the desired chip form.

The pulsating HP CF supply strategy was less investigated in the past. Rasch et al. carried out finish turning experiments with different aluminum alloys and steel materials [24]. The influence of continuous HP CF supply on chip breakage was analyzed as well as pulsating HP CF supply. To realize a pulsating CF supply, a $2 / 2$ way valve was implemented in the cutting fluid circuit to interrupt the cutting fluid jet. Rasch concluded that the pulsating HP CF supply was less suitable for reliable chip breakage than the continuous HP CF supply, because appropriate chip breakage was achieved for a smaller number of materials and area of operability.

Cayli investigated surface anomalies on finished workpiece surfaces caused by chip impact due to HP CF supply [11]. It has been found that the chips are accelerated in the direction of the jet immediately after the fracture because their center of gravity is located in the focus of the CF jet. Cayli proposed the pulsating cutting fluid supply in two pressure stages. The aim of this technology was to reduce the CF supply pressure until the chip length increases and the center of gravity of the chip is shifted out of the jet focus. First experiments during turning of Inconel 718 with a CF supply pressure of $p_{\mathrm{CF}}=150$ bar were carried out. For the realization of the pulsating supply, a proportional valve was used, which reduced the flow rate by $50 \%$ during the time interval of low pressure. The high- and lowpressure time intervals were chosen to be of equal length and experiments were performed with pulse frequencies of $1 \mathrm{~Hz}, 2$ $\mathrm{Hz}$, and $3 \mathrm{~Hz}$. A tendency to increasing chip length with decreasing pulse frequency was observed.

Bergs et al. further investigated the pulsating cutting fluid supply strategy during finish turning of Inconel 718 [14, 25, 26]. A valve unit, which enabled an individual adjustment of the duration and CF supply pressure of the high- and lowpressure time intervals, was used. As the present research work is based on these investigations, the experimental setup is further explained in Section 3. Initial experiments included the characterization of the pulsating cutting fluid jet by measurements of the jet force in the cutting edge area and high- speed camera studies. Furthermore, suitable supply pressures for the high- and low-pressure time intervals related to the cutting parameters were identified. It was shown that the chip length can be specifically influenced by the pulsating CF supply parameters. The duration of the time interval of the reduced supply pressure determined the chip length $l_{\mathrm{s}}$ significantly. An approximate proportional relationship between the path length due to primary motion $l_{\mathrm{c}}$, the duration of the time interval of reduced pressure 'closed' $t_{\mathrm{CP}}$ and the chip length $l_{\mathrm{s}}$ was identified. In accordance with this, the chip length increased with a rising cutting speed at a constant time interval 'closed'. The influence of the feed $0.15 \mathrm{~mm} \leq f \leq 0.25 \mathrm{~mm}$ and the cutting depth $0.3 \mathrm{~mm} \leq a_{p} \leq 0.4 \mathrm{~mm}$ on the chip length $l_{\mathrm{s}}$ was classified as low in the examined area.

Sterle et al. analyzed the pulsating HP CF supply strategy in comparison to HP CF supply and cryogenic machining concerning economic and ecological aspects [27]. Turning experiments in Inconel 718 with pulsating HP CF supply were carried out with a feed $f=0.28 \mathrm{~mm}$, a cutting speed $v_{c}=50$ $\mathrm{m} / \mathrm{min}$, and a depth of cut $a_{p}=0.5 \mathrm{~mm}$. A low-pressure pulse with a length of $140 \mathrm{~ms}$ and a supply pressure of 1 bar was defined. The HP pulse time was $60 \mathrm{~ms}$ at a supply pressure of 200 bar. Chip breakage was improved in contrast to the continuous HP CF supply due to the dynamic behavior of the pulsating jet and its sudden impact on the chip. The upcurl radii of the resulting chips changed along the chip length due to the pulsating jet.

In summary, the pulsating HP CF supply was identified as a suitable technology to achieve chip breakage during finish turning of Inconel 718 by Bergs et al. and Sterle et al. [14, 25-27]. Bergs identified basic correlations between the cutting parameters, the pulsation parameters, and the resulting chip length $l_{\mathrm{s}}$ [25]. In this paper, these relationships were examined in detail and an approach to predict chip length $l_{\mathrm{s}}$ using regression modelling was developed. Furthermore, the effects of the pulsating CF supply on the resulting workpiece surfaces were investigated.

\section{Experimental setup}

All cutting experiments were conducted on a $\mathrm{CNC}$ lathe of the type NEF 600 of the company DMG MORI. The machine tool provides a maximum spindle drive power of $P=28 \mathrm{~kW}$ and a maximum rotational speed of $n=3500 \mathrm{~min}^{-1}$. A pressureregulated high-pressure pump of the company ChipBlaster was used to provide the cutting fluid. It generates a maximum CF supply pressure of $p=350$ bar at a flow rate of $Q=40$ $1 / \mathrm{min}$. The CF was an emulsion with a concentration of $8 \%$ of the type Vasco TP 519 of the company Blaser Swisslube.

As described before, the functional principle of pulsating HP CF supply is based on two alternating CF supply pressure stages. They are realized by a prototype of a pulse unit which 
was provided by the company mueller co-ax AG. The functional principle of the pulse unit is shown in Fig. 1. During the low-pressure stage, defined by the duration of the time interval 'closed' $t_{\mathrm{CP}}$ and the reduced $\mathrm{CF}$ supply pressure $p_{\mathrm{CP}}$, the $\mathrm{CF}$ is diverted into a throttled pipe. Consequently, the $\mathrm{CF}$ flow rate and following the supply pressure are reduced, the force of the cutting fluid jet does not lead to chip breakage, and the chip length increases. When the HP stage begins, the valve switches to the position 'open' and a HP pulse $p_{O P}$ is released. The valve lasts in position 'open' for the duration of the time interval 'open' top.

A tool holder of the type PCLNL 2525M-12-JHP from the company ISCAR was used for all cutting experiments. It was designed for targeted HP CF supply up to $p_{\mathrm{CF}}=300$ bar. A nozzle with a diameter of $D=$ $1.6 \mathrm{~mm}$ was positioned above the cutting insert. Consequently, the $\mathrm{CF}$ jet was focused on the rake face. The flank-face-sided outlet of the tool holder was sealed. The tool holder was equipped with an indexable insert of the type CNMG 120408-F3M IC806 of the company ISCAR. Each insert was used for one to three cutting experiments with a cutting time of $t_{\mathrm{h}} \approx 40 \mathrm{~s}$. Tool life tests proved that there is only minimal tool wear at this point and the influence of tool wear on chip formation can be neglected [26]. External cylindrical finish turning tests with cutting speeds between 50 $\mathrm{m} / \mathrm{min} \leq v_{\mathrm{c}} \leq 80 \mathrm{~m} / \mathrm{min}$, feeds of $0.1 \mathrm{~mm} \leq f \leq 0.25$ $\mathrm{mm}$, and depths of cut of $0.3 \mathrm{~mm} \leq a_{\mathrm{p}} \leq 0.5 \mathrm{~mm}$ were conducted on finished workpieces (Fig. 4) with the nickel-based alloy Inconel 718. The parameters were selected based on industrial standards for finish turning of Inconel 718 with coated carbide inserts. The mechanical properties and chemical composition of the material are shown in Table 1 and Table 2.

Based on the identified suitable pressure levels in previous research work [14], a CF supply pressure of $p_{\mathrm{CP}}=40$ bar was chosen for the time interval 'closed'. During the HP time interval $t_{\mathrm{OP}}$ a supply pressure of $p_{\mathrm{OP}}=127$ bar was set. This led to CF flow rates of $Q_{\mathrm{OP}}=16 \mathrm{l} / \mathrm{min}$ and $Q_{\mathrm{CP}}=10 \mathrm{l} / \mathrm{min}$ with the used experimental setup. For all investigated cutting parameters,

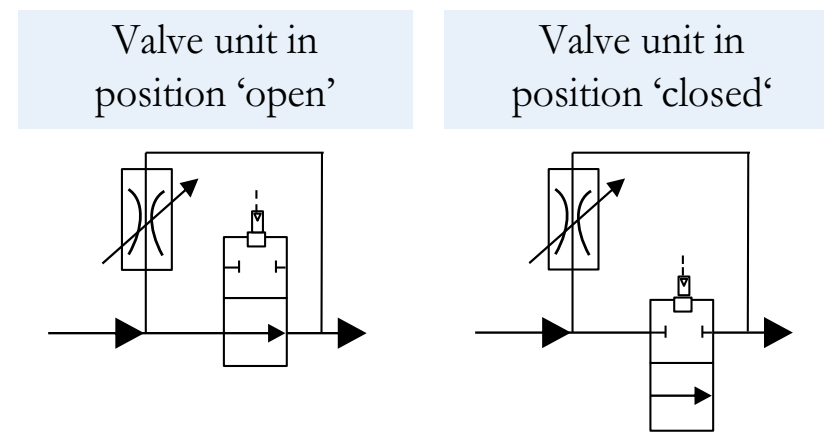

Fig. 1 Valve unit for pulsating HP CF supply [14] it was ensured that turning processes with a continuous CF supply at $p_{\mathrm{CF}}=p_{\mathrm{CP}}=40$ bar led to the formation of long helical chips. Bergs et al. showed that time intervals 'open' $t_{\mathrm{OP}} \geq 100 \mathrm{~ms}$ caused the occurrence of a high amount of small chips which were broken during the time interval 'open' [14]. Additionally, time intervals 'open' with $t_{\mathrm{OP}}<50 \mathrm{~ms}$ could not be realized by the used system. Time intervals 'closed' of $t_{\mathrm{CP}}>$ $1500 \mathrm{~ms}$ led to the formation of very long helical chips, which may cause similar effects to the chips resulting from conventional flood cooling. In this area, chip control that contributes to process reliability cannot be realized. Therefore, the time interval 'closed' was varied between $500 \mathrm{~ms} \leq t_{\mathrm{CP}} \leq 1500 \mathrm{~ms}$, and the time interval 'open' was set between $50 \mathrm{~ms} \leq t_{\mathrm{OP}} \leq 100 \mathrm{~ms}$.

Three cutting test series were carried out. The aim of the first test series 'chip length' was to achieve an initial understanding of the influence of the cutting parameters and the time intervals $t_{\mathrm{OP}}$ and $t_{\mathrm{CP}}$ on the chip length $\mathrm{l}_{\mathrm{s}}$, which is caused by the pulsating jet. Therefore, only the chips that were divided into approximately equal lengths, by the pulsation were taken into account in the evaluation, as shown in Fig. 2. Chips, which were not broken by the impact of one HP pulse, were not taken into concern.

Furthermore, the objective of these experiments was to describe the identified relationship between the parameters and the chip length caused by the pulsating jet by an equation by the use of regression modelling. For each parameter set, the lengths of the chips from at least two cuts were used for regression modelling and for visualizing the average length in diagrams. Regression modelling was done with Minitab ${ }^{\circledR}$ Statistical Software 17 of the company Minitab. A linear regression was performed with the least square method based on the length of more than 900 measured chips resulting from cutting experiments with feeds of $0.15 \mathrm{~mm} \leq f \leq 0.25 \mathrm{~mm}$ and depths of cut of $0.3 \mathrm{~mm} \leq a_{\mathrm{p}} \leq 0.4 \mathrm{~mm}$. Additionally, crosssections and longitudinal sections of chips were prepared and dip etched for $60 \mathrm{~s}$ using Kalling's reagent, as shown in Fig. 3.

The aim of the second experimental series 'chip length distribution' was to determine the proportion of chips, which were successfully broken by the HP pulse, in the total removed material in dependence on the set parameters.

Therefore, the weight of the removed material was calculated for every cut. After the machining process, every chip which was longer than $l_{\mathrm{s}}=40 \mathrm{~mm}$ was collected, measured, and weighed. The center of gravity of these chips of this length lies significantly outside the focus of the impinging $\mathrm{CF}$ jet. It is, therefore, assumed that this length contributes to reducing surface damage. Additionally, the second test series was used to verify the regression equation for the prediction of chip length. 
Table 1 Mechanic properties of Inconel 718 [28]

\begin{tabular}{llll}
\hline Tensile strength $\mathrm{Rm} / \mathrm{MPa}$ & Yield strength $\mathrm{Rp}_{0,2} / \mathrm{MPa}$ & Elongation at break A / \% & $\begin{array}{l}\text { Elastic modulus } \\
\mathrm{E} / \mathrm{GPa}\end{array}$ \\
\hline$\geq 1230$ & $\geq 1030$ & $\geq 12$ & 205 \\
\hline
\end{tabular}

In the third experimental series 'surface finish', a case study was done to investigate the effect of the different cutting fluid supply strategies on the workpiece surface. The procedure is shown in Fig. 4. Each experiment was started with a face finish turning operation.

Following, the cylindrical surface was finished five times with a continuous or pulsating CF supply parameter set. This leads to a cutting time of $t_{\mathrm{c}}=516 \mathrm{~s}$ for each insert used at a cutting speed of $v_{\mathrm{c}}=60 \mathrm{~m} / \mathrm{min}$. Previous tool life tests showed that the expected maximum width of flank wear land is $V B_{\max }$ $>100 \mu \mathrm{m}$ at the end of the experiment [26], whereby tool wear was taken into account in this test series. The cutting and CF supply parameters are shown in Fig. 5. Workpiece one was machined with a continuous CF supply at $p_{\mathrm{CF}}=p_{\mathrm{OP}}=127$ bar.

The investigations were concluded by an analysis of the frontal surface by different methods. In a first step, an optical qualitative evaluation of the surface using a digital microscope of the type VHX 5000 from the company Keyence was conducted. Furthermore, the topography of the surface was measured with the surface measuring station MarSurf LD 260 of the company Mahr. For this purpose, three squares of $2 \times 2$ $\mathrm{mm}^{2}$, shifted by an angle of $120^{\circ}$, were analyzed on each workpiece. The squares were started at a distance of about $2 \mathrm{~mm}$ from the workpiece shoulder and the measurement was conducted radially from the inside to the outside. The distance between the measuring lines was $10 \mu \mathrm{m}$ and the increment was $0.5 \mu \mathrm{m}$. For the evaluation of the measurements, the software MountainsMap ${ }^{\circledR}$ Universal 7.3.7746 of the company Digital Surf was used.

In addition to the illustration of 3-dimensional profile views for qualitative assessment, the area roughness parameters arithmetical mean height $\mathrm{Sa}$, maximum peak height $\mathrm{Sp}$, and maximum height $\mathrm{Sz}$ were taken into concern [30].

Table 2 Chemical composition of Inconel 718 [29]

\begin{tabular}{lllll}
\hline Element & $\mathbf{N i}$ & $\mathbf{C r}$ & $\mathbf{N b}$ & Mo \\
\hline Share / \% wt. & $50.0-55.0$ & $17.0-21.0$ & $4.75-5.5$ & $2.8-3.3$ \\
Element & $\mathbf{T i}$ & $\mathbf{A l}$ & $\mathbf{C o}$ & $\mathbf{C}$ \\
Share / \% wt. & $0.65-1.15$ & $0.2-0.8$ & $\leq 1.0$ & $\leq 0.08$ \\
Element & $\mathbf{M n}$ & $\mathbf{S i}$ & $\mathbf{P}$ & $\mathbf{S}$ \\
Share / \% wt. & $\leq 0.35$ & $\leq 0.35$ & $\leq 0.015$ & $\leq 0.015$ \\
Element & $\mathbf{B}$ & $\mathbf{C u}$ & $\mathbf{F e}$ & \\
Share / \% wt. & $\leq 0.006$ & $\leq 0.3$ & Balance & \\
\hline
\end{tabular}

\section{Results and discussion}

\subsection{Chip length}

According to the operating principle of the pulsating HP CF supply, the chip is not broken during the time interval 'closed' $t_{\mathrm{CP}}$. At the beginning of the HP time interval 'open', the chip is then broken by the impact of the jet. If this is the case, the resulting chip length $l_{\mathrm{s}}$ is directly related to the path length due to primary motion $l_{\mathrm{c}}$, covered in the time interval $t_{\mathrm{CP}}$. In Fig. 6 , two longitudinal sections of a chip are shown. The section of the last winding of the chip exhibits a stronger deformation and a decreased radius compared to the shape of the same chip at half chip length $l_{\mathrm{s}}$. This can be attributed to the increased acting force of the jet from the beginning of the time interval 'open'. This strongly deforms the chip until it finally breaks.

When machining Inconel 718, the type of chip formation may change from continuous to lamellar formation depending on the applied cutting parameters such as the cutting speed or the feed [31]. A tendency to the formation of shear bands due to the increased deformation was identified at the end of the chip. Chip breaking is enhanced by the segmentation of the chip [31].

In Fig. 7, the resulting chip length $l_{\mathrm{s}}$ is shown as a function of the time interval 'closed' $t_{\mathrm{CP}}$. Based on the previous work on the pulsating HP CF supply, an almost linear relationship between the time $t_{\mathrm{CP}}$ and chip length $l_{\mathrm{s}}$ was expected $[14,25$, 26]. First, all cutting parameters were kept constant and only the length of the time interval $t_{\mathrm{CP}}$ was varied at a cutting speed of $v_{\mathrm{c}}=60 \mathrm{~m} / \mathrm{min}$. At constant cutting speed, the chip length $l_{\mathrm{s}}$ increases proportionally to the length of the time interval $t_{\mathrm{CP}}$. Furthermore, the chip length increases with constant time $t_{\mathrm{CP}}$ and increasing cutting speed (blue squares in Fig. 7). Hence, the pulsating HP CF supply is a suitable technology to set a certain chip length in the examined parameter range. It is expected that the chip length $l_{\mathrm{s}}$ can be expressed by a function

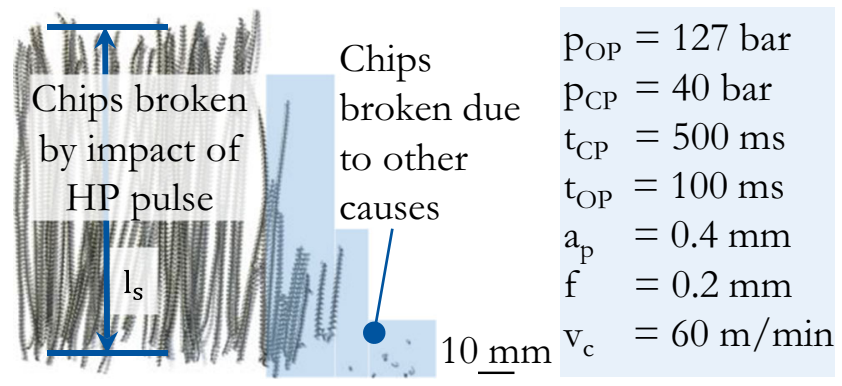

Fig. 2 Collected chips of one cutting experiment 


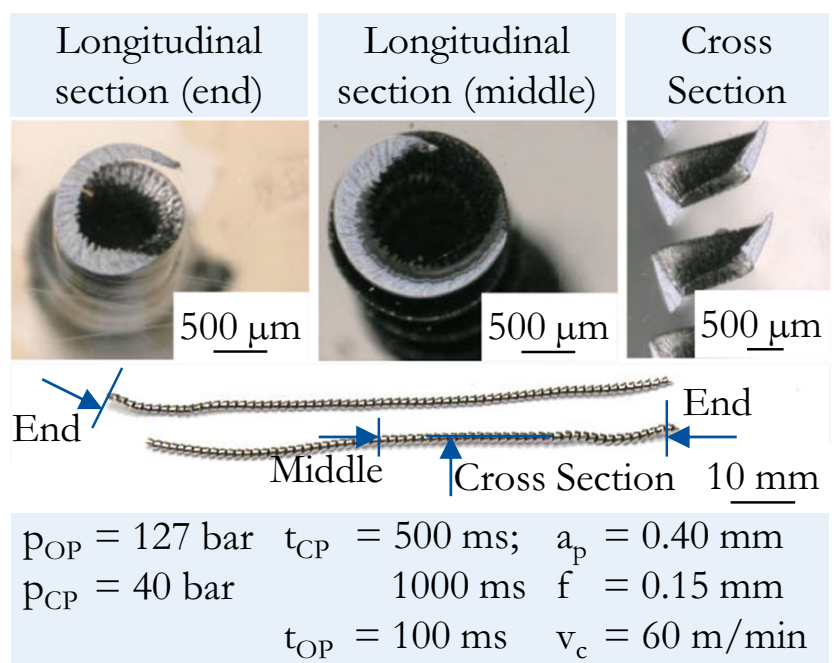

Fig. 3 Prepared sections of the chips

with the cutting conditions and CF supply parameters as coefficients.

Courbon et al. reported a decreased chip size and a better chip breakability due to an increase of the cutting speed at the same CF supply pressure [18]. According to the results, this effect is compensated by the described relations during pulsating HP CF supply in the investigated area. Additionally, chip breakability and consequently chip length are influenced by the feed $f$ and the crosssection of the undeformed chip A [13]. The results of the cutting experiments concerning the influence of the feed $\mathrm{f}$ and the cross-section of the undeformed chip A on the chip length are shown in Fig. 8. As the feed does not influence the path length due to primary motion $l_{\mathrm{c}}$ during the time interval $t_{\mathrm{CP}}$, changes of the resulting chip length $l_{\mathrm{s}}$ can be attributed to the chip thickness ratio and perhaps increased breakability. Although an increased feed rate promotes chip breaking [18], the cutting tests with a higher feed of $f=0.2 \mathrm{~mm}$ resulted in a similar chip length in comparison to the investigations with a feed of $f$ $=0.15 \mathrm{~mm}$. A reduced depth of cut $\mathrm{a}_{\mathrm{p}}=0.3 \mathrm{~mm}$ led to a marginally decreased chip length.

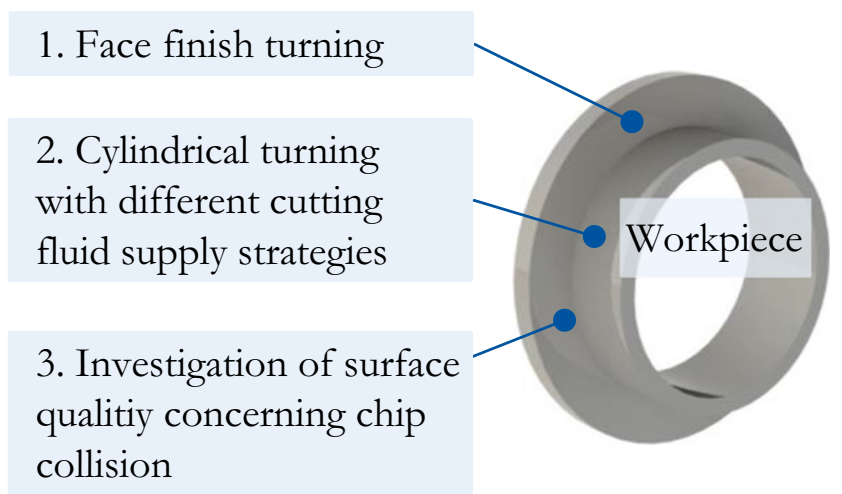

Fig. 4 Procedure of test series 3 'surface finish'

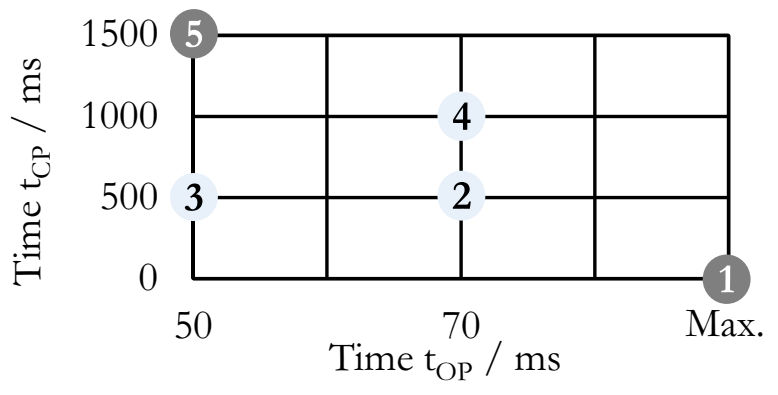

x Workpiece $\mathrm{v}_{\mathrm{c}}=60 \mathrm{~m} / \mathrm{min} \mathrm{x} \mathrm{v}_{\mathrm{c}}=80 \mathrm{~m} / \mathrm{min}$ $\mathrm{P}_{\text {OP }}=127$ bar $\mathrm{a}_{\mathrm{p}}=0.40 \mathrm{~mm} \quad \mathrm{v}_{\mathrm{c}}=60 ; 80 \mathrm{~m} / \mathrm{min}$ $\mathrm{p}_{\mathrm{CP}}=40 \mathrm{bar} \mathrm{f}=0.15 \mathrm{~mm} \quad$ Inconel 718

Fig. 5 Applied parameter sets in the case study

These differences can be accounted to the varied crosssection of the chip due to the changed parameters. An enlarged cross-section of the undeformed chip improves its area moment of inertia and consequently its stability against the impinging CF jet. As shown in Fig. 9, a higher feed $f$ led to an increase in the thickness of the deformed chip h', as expected. The reduced depth of cut $a_{p}=0.3 \mathrm{~mm}$ resulted in a smaller width of the deformed chip b'. Due to the small depth of cut $a_{p}$, the tool is exclusively engaged in the area of the tool cutting edge radius. In consequence of the resulting chip flow angle the jet does not impinge orthogonally on the back of the chip.

The results of the cutting tests indicate that the width of the chip b' was the decisive measure for the breakability of the chip in the investigated parameter range.

The regression analysis showed that the relation between the cutting and cutting fluid supply parameters and the resulting chip length $l_{\mathrm{s}}$ is described by the following Eq. (1). The equation is applicable only in the studied parameter range.

Chip at half $1_{\mathrm{s}}$

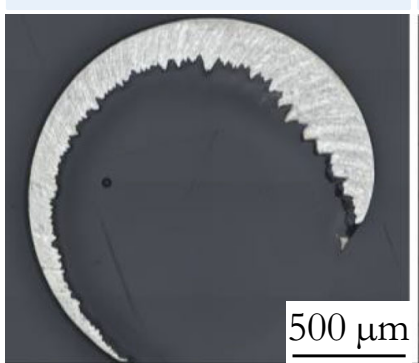

$$
\begin{array}{lll}
\mathrm{P}_{\mathrm{OP}}=127 \mathrm{bar} & \mathrm{t}_{\mathrm{CP}}=1000 \mathrm{~ms} & \mathrm{a}_{\mathrm{p}}=0.40 \mathrm{~mm} \\
\mathrm{P}_{\mathrm{CP}}=40 \mathrm{bar} & \mathrm{t}_{\mathrm{OP}}=100 \mathrm{~ms} & \mathrm{f}=0.15 \mathrm{~mm} \\
& & \mathrm{v}_{\mathrm{c}}=60 \mathrm{~m} / \mathrm{min}
\end{array}
$$

Fig. 6 Longitudinal sections of the chips 


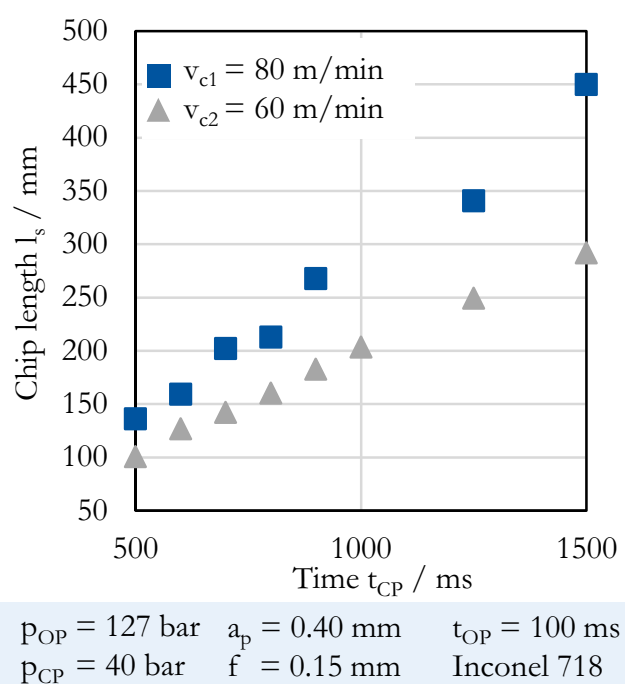

Fig. 7 Influence of $t_{\mathrm{CP}}$ and cutting speed $v_{\mathrm{c}}$ on chip length $l_{\mathrm{s}}$

$$
\begin{aligned}
l_{s}=- & 174.4 \mathrm{~mm}+3.33 \frac{\mathrm{mm}}{\frac{\mathrm{m}}{\mathrm{min}}} \cdot v_{c}+40.9 \cdot a_{p} \\
& -256.7 \cdot f+0.19319 \frac{\mathrm{mm}}{\mathrm{ms}} \cdot t_{C P}
\end{aligned}
$$

The model explains $R=88 \%$ of the scatter of the chip length. As expected, the main effect analysis identified the time interval 'closed' $t_{\mathrm{CP}}$ as the strongest influence on the chip length, followed by the cutting speed $v_{\mathrm{c}}$. These are the variables that influence the path length due to primary motion $l_{\mathrm{c}}$ between two HP pulses. Based on the main effect analysis, the chip length is reduced by increasing feed $f$ and slightly extended by increasing depth of cut $a_{\mathrm{p}}$. Further experiments with a depth of cut of $a_{\mathrm{p}}=0.5 \mathrm{~mm}$ and feeds between $0.1 \mathrm{~mm} \leq f \leq$

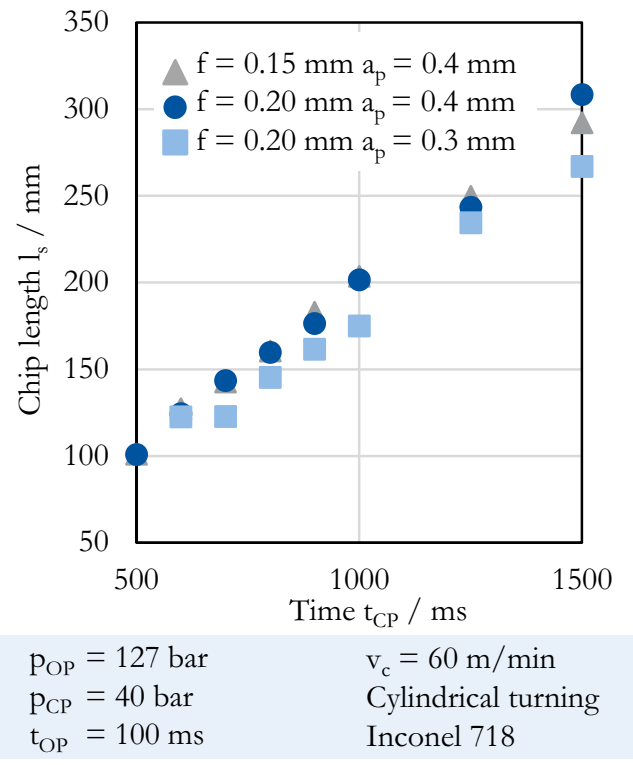

Fig. 8 Influence of feed $f$ and depth of cut $a_{\mathrm{p}}$ on chip length

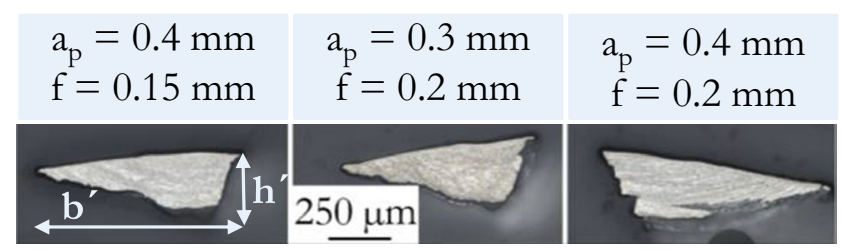

Fig. 9 Cross sections of the chips

$0.2 \mathrm{~mm}$ resulted in an extended chip length with increasing feed $\mathrm{f}$ due to the enlarged cross-section of the undeformed chip and the resulting higher stability of the emerging chip. Consequently, it is assumed that the effect of the feed $\mathrm{f}$ on the chip length $l_{\mathrm{s}}$ depends on the depth of cut $a_{\mathrm{p}}$. One way to improve the regression model would be to include the additional data and further cutting experiments with variations of the depth of cut $a_{\mathrm{p}}$ and feed $\mathrm{f}$ to identify possible interactions.

\subsection{Chip length distribution}

During the second test series, every chip with a length over $l_{\mathrm{s}} \geq$ $40 \mathrm{~mm}$ was collected, weighed, and measured. The centre of gravity of chips of this length lies significantly outside the focus of the impinging $\mathrm{CF}$ jet. It was therefore assumed that this length contributes to reducing surface damage. The influence of the time interval 'closed' $t_{\mathrm{CP}}$ on the distribution of the resulting chip length is shown in Fig. 10. At a time interval of $t_{\mathrm{CP} 1}=500 \mathrm{~ms}$, chips of lengths between $100 \mathrm{~mm} \leq l_{\mathrm{s}} \leq$ $110 \mathrm{~mm}$ accounted for the largest weight share of $w=48 \%$ of the removed material. The second-largest share of $w=8 \%$ was represented by chips with a length of $90 \mathrm{~mm} \leq l_{\mathrm{s}} \leq 100$ $\mathrm{mm}$. Furthermore, the diagram shows that a small proportion of shorter chips occurred. These chips may have been broken

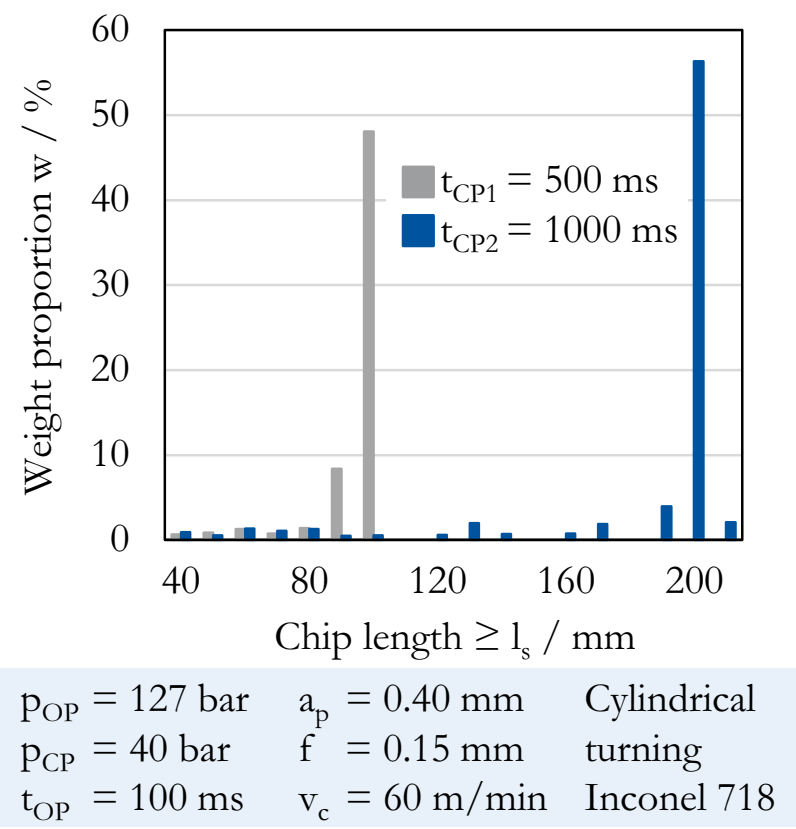

Fig. 10 Influence of $t_{\mathrm{CP}}$ on chip length distribution 
again after the actual machining process by contact with other chips or the chuck.

Additionally, it cannot be excluded that the HP CF jet causes more than one chip breakage during the time interval $t_{\mathrm{OP}}=100 \mathrm{~ms}$. Entering the set parameters in the regression equation for the time interval $t_{\mathrm{CP} 1}=500 \mathrm{~ms}$ results in Eq. (2):

$$
\begin{aligned}
l_{s 500} & =-174.4 \mathrm{~mm}+3.33 \frac{\mathrm{mm}}{\mathrm{m} / \mathrm{min}} \cdot 60 \frac{\mathrm{m}}{\mathrm{min}} \\
& +40.9 \cdot 0.4 \mathrm{~mm}-256.7 \cdot 0.15 \mathrm{~mm} \\
& +0.19319 \frac{\mathrm{mm}}{\mathrm{ms}} \cdot 500 \mathrm{~ms}=99.85 \mathrm{~mm}
\end{aligned}
$$

Furthermore, the time interval $t_{\mathrm{CP} 2}=1000 \mathrm{~ms}$ results in a predicted chip length of Eq. (3):

$$
\begin{gathered}
l_{s 1000}=-174.4 \mathrm{~mm}+3.33 \frac{\mathrm{mm}}{\mathrm{m} / \mathrm{min}} \cdot 60 \frac{\mathrm{m}}{\mathrm{min}} \\
+40.9 \cdot 0.4 \mathrm{~mm}-256.7 \cdot 0.15 \mathrm{~mm} \\
+0.19319 \frac{\mathrm{mm}}{\mathrm{ms}} \cdot 1000 \mathrm{~ms}=196.5 \mathrm{~mm}
\end{gathered}
$$

The predicted values correspond to the length of the chips shown in the diagram in Fig. 10. The equation is therefore suitable for predicting the chip length in the examined area. The specific adjustment of the chip length could be reproduced in the second test series.

As shown in Fig. 11, the lower cutting speed $v_{c 2}=60 \mathrm{~m} /$ min led to a larger proportion of chips with a length of $l_{\mathrm{s}} \geq$ $40 \mathrm{~mm}$ compared to the higher cutting speed $v_{\mathrm{c} 1}=80 \mathrm{~m} / \mathrm{min}$. With a higher cutting speed, the path length due to primary motion covered in the time interval 'open' $t_{\mathrm{OP}}$ increases.

Consequently, the probability of additional chip breakage during the HP stage increases and more small chips occur. The longer the time interval 'closed' $t_{\mathrm{CP}}$ is selected, the less frequently the HP pulse is released. Correspondingly, the

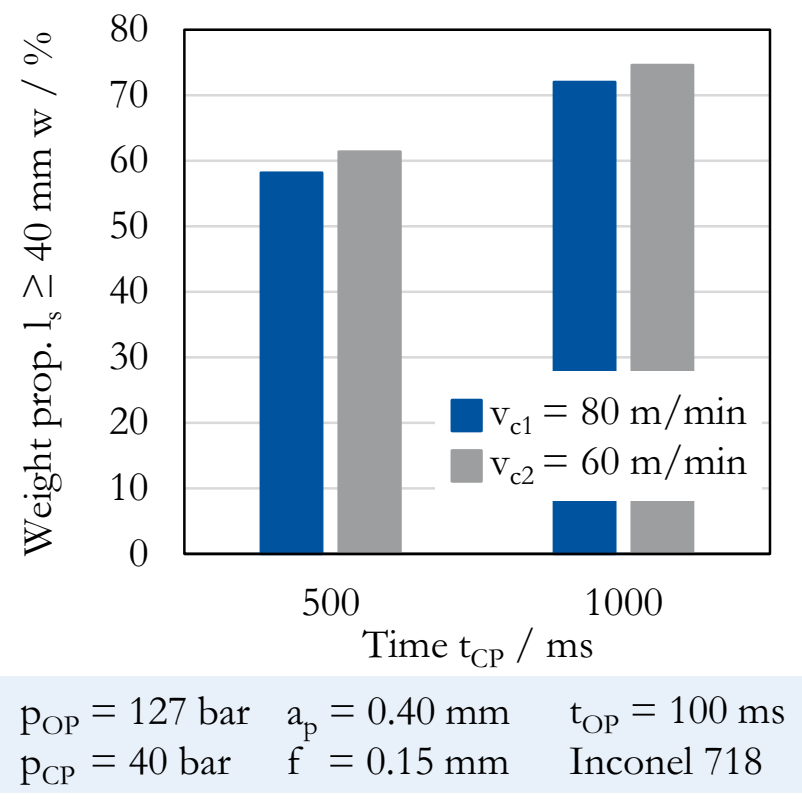

Fig. 11 Influence of $t_{\mathrm{CP}}$ on share of chips $l_{\mathrm{s}} \geq 40 \mathrm{~mm}$ proportion of chips with a length $l_{\mathrm{s}} \geq 40 \mathrm{~mm}$ enlarges with the longer investigated time interval $t_{\mathrm{CP} 2}=1000 \mathrm{~ms}$.

To investigate this effect further, the length of the time interval 'open' was varied. The results are shown in Fig. 12. A reduction of the time interval open led to a larger variation of the chip length.

Especially with the minimum investigated time interval 'open' of $t_{\mathrm{OP} 1}=50 \mathrm{~ms}$, several chips were broken only after two or three HP stages. The predictability of the chip length was therefore impaired by the reduction of the time interval $t_{\mathrm{OP}}$. The force of the CF jet does not act on the chip long enough to break it reliably. In contrast, at the longest investigated time interval $t_{\mathrm{OP} 3}=100 \mathrm{~ms}$, no chips longer than predicted occurred.

As shown in Fig. 13, the lowest time interval $t_{\mathrm{OP} 1}=50 \mathrm{~ms}$ led to the highest weight percentage of chips with a length over $l_{\mathrm{s}} \geq 40 \mathrm{~mm}$ of $w=77 \%$. The longest time interval $t_{\mathrm{OP} 3}$ $=100 \mathrm{~ms}$ results in a maximum weight share of $w=61 \%$. As described above, the lower cutting speed of $v_{\mathrm{c} 2}=60 \mathrm{~m} / \mathrm{min}$ has a positive effect on the weight percentage of chips with a length $l_{s} \geq 40 \mathrm{~mm}$.

\subsection{Surface finish}

Figures 14 and 15 show the frontal surfaces of the workpieces of the case study after finishing the cylindrical surface with varied CF supply parameters. The left edge of each picture is situated at the shoulder of the cylindrical surface. The front surface after a cutting experiment with continuous CF supply at $p_{\mathrm{CF}}=p_{\mathrm{CP}}=40$ bar is shown on the left side of Fig. 14. No

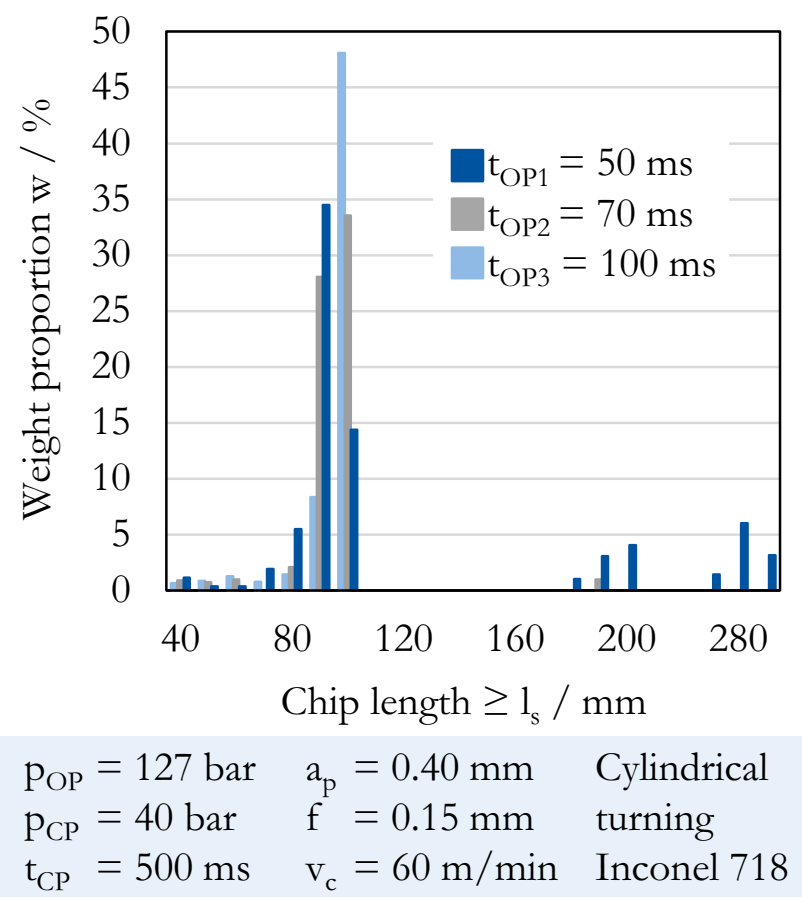

Fig. 12 Influence of $t_{\mathrm{OP}}$ on chip length distribution 


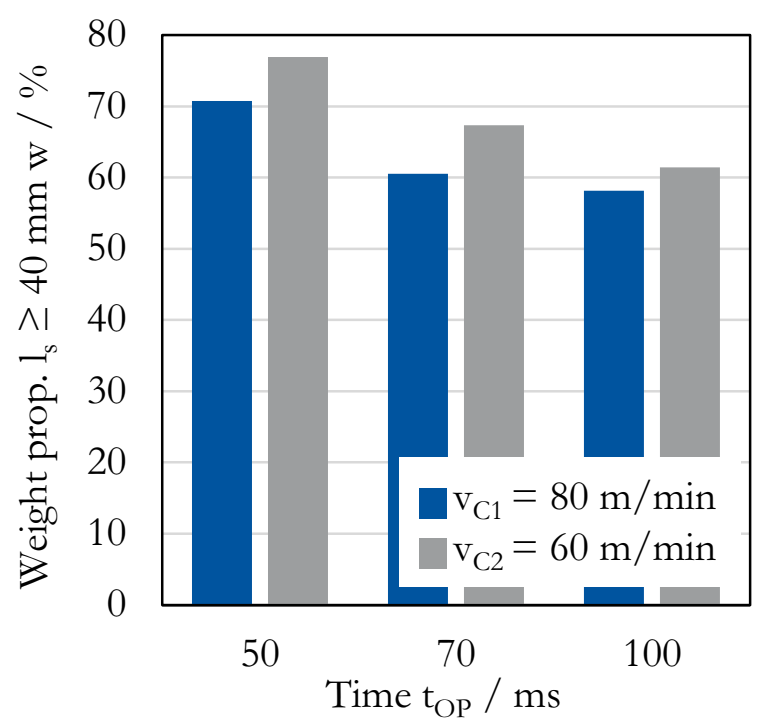

$$
\begin{array}{lll}
\text { POP }_{\text {OP }}=127 \text { bar } & a_{p}=0.40 \mathrm{~mm} & t_{C P}=500 \mathrm{~ms} \\
\text { P }_{C P}=40 \text { bar } & f=0.15 \mathrm{~mm} & \text { Inconel } 718
\end{array}
$$

Fig. 13 Influence of $t_{\mathrm{OP}}$ on share of chips $l_{\mathrm{s}} \geq 40 \mathrm{~mm}$

damages due to chip collision were detected. In contrast, after finish turning with continuous HP CF supply at a pressure of $p_{\mathrm{CF}}=p_{\mathrm{OP}}=127 \mathrm{bar}$, the surface was speckled with traces of chip contact that appear as dark lines on the surface. In between, there are more severe damages of the surface, which are marked by yellow circles in the images. Based on the microscopic images, it cannot be clearly determined whether these are scratches, missing material, or material adhesions.

As shown in Fig. 15, by the application of the pulsating HP CF supply technology with time intervals $t_{\mathrm{CP}}=500 \mathrm{~ms}$ and $t_{\mathrm{OP}}=70 \mathrm{~ms}$, the traces of chip contact were considerably reduced and the number of severe damages was decreased on the front face of workpiece 2. Nevertheless, traces of chip contact as well as severe damages were detected.

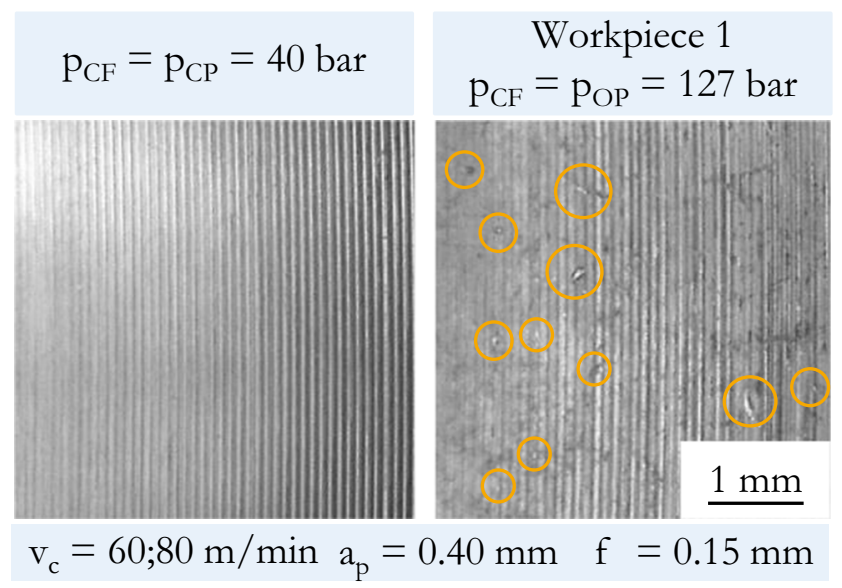

Fig. 14 Frontal surface after finish turning with conventional CF supply parameters

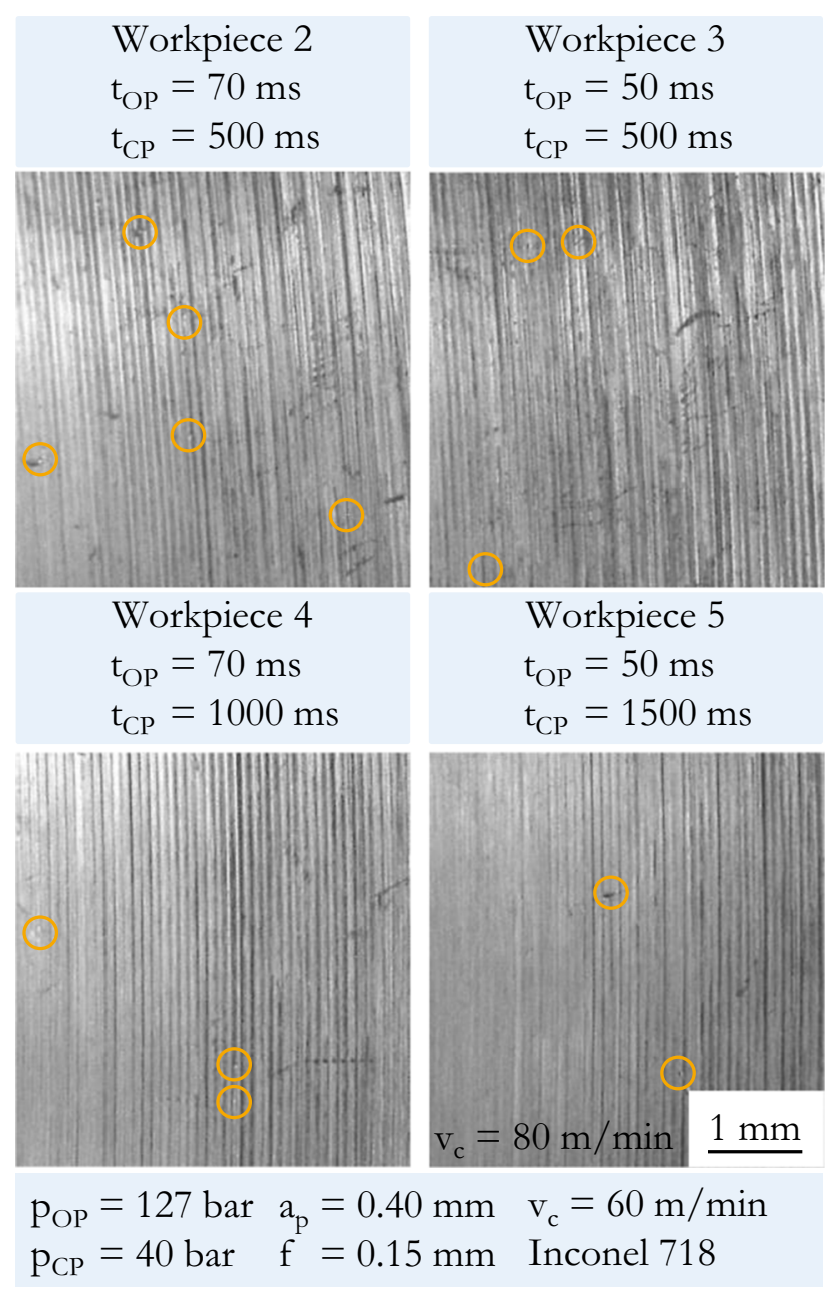

Fig. 15 Frontal surface after finish turning with pulsating CF supply

The experiments concerning the chip length distribution showed that each a reduction of the time interval 'open' and an extension of the time interval 'closed' led to an increased weight proportion of chips with $l_{\mathrm{s}} \geq 40 \mathrm{~mm}$. It was assumed that the amount of chips with this length is related to the quality of the front surface. Based on these findings, workpiece 3 was machined with a reduced time interval 'open' of $t_{\mathrm{OP}}=50 \mathrm{~ms}$. An increased time interval $t_{\mathrm{CP}}=1000 \mathrm{~ms}$ was applied during turning of workpiece 4 . Both changes led to a reduction of countable surface damages compared to workpiece 2. During turning of workpiece 5 , a higher cutting speed of $v_{\mathrm{c}}=80 \mathrm{~m} / \mathrm{min}$ and a further increased time interval closed $t_{\mathrm{CP}}=1500 \mathrm{~ms}$ were set. The qualitative microscopic evaluation of the surfaces indicated that workpiece 5 had very little surface damage.

Due to the pulsating CF supply, a similar good surface condition as with the continuous low-pressure CF supply was detected in large subareas of the surface.

Since the microscopic images do not enable any determination of the height or depth of the surface damage, the topography of the surfaces was analyzed in more detail. 
Figure 16 contains the topographic 3-dimensional view of a $2 \times 2 \mathrm{~mm}^{2}$ square of the surface of workpiece 1 . It can be seen that the stripes perceived as scratches in Fig. 14 are adhering material. The color scale indicates the profile heights. It can be clearly seen that the areas visually perceived as scratches in Fig. 14 are aligned material adhesions or less frequently pullouts caused by an impacting chip. The adhesions occur in the peaks and in the grooves of the profile of the turned surface. Furthermore, the surface exhibits individual punctual damages, which are both material adhesions and pullouts.

Figure 17 shows an example of a surface profile of $4 \mathrm{~mm}^{2}$ of each of the other four workpieces. The surface of workpiece 2 exhibited both material adhesion and notable material pullouts in the profile peaks. Similar to the optical micrographs, a significant reduction in damages due to the adjustment of the CF supply parameters was identified for workpieces 3-5. Small material adhesions and pullouts occurred on the surface of workpiece 3. In the illustration of the surface of workpiece 3 , it can also be seen that the collision of a chip with the surface can lead to material adhesion and pullout simultaneously. No measurable damages were detected at any of the three measuring positions of workpiece 4 . Slight damage was identified on the surface of workpiece 5 . The results of the qualitative evaluation based on the 3-dimensional profile views are consistent with the surface characteristics according to DIN ISO 25178 [30], as shown in Fig. 18. The bars in the diagram each represent the average value of the three analyzed squares of one workpiece. The arithmetical mean height Sa of the surfaces was similar for the front faces of all workpieces due to the preliminary turning process.

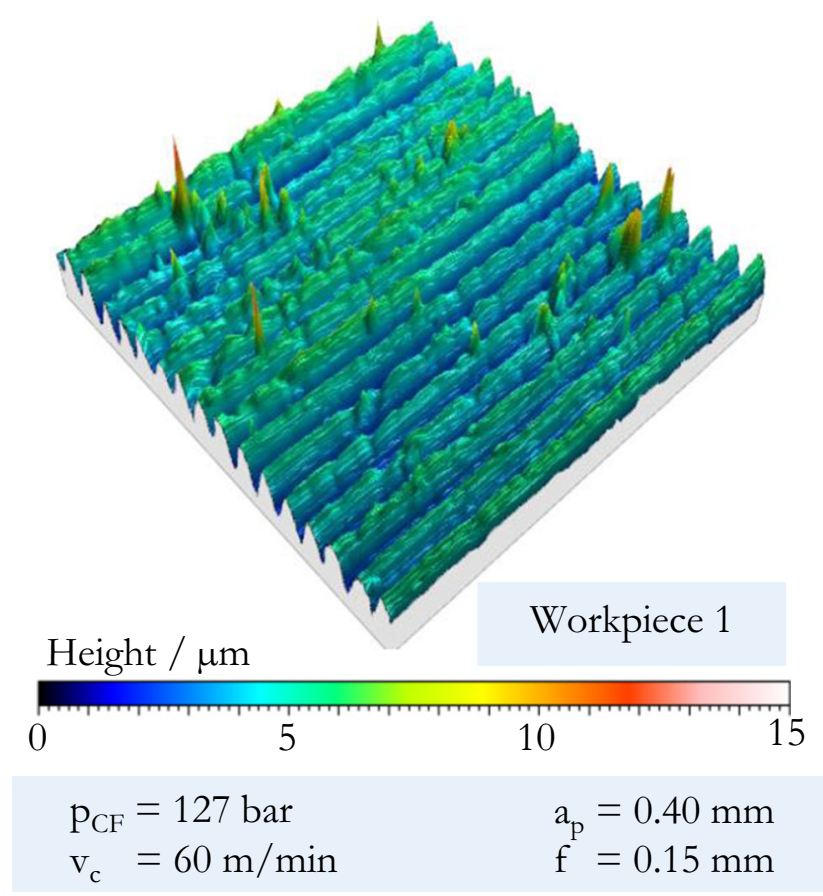

Fig. 16 Topographic 3-dimensional view of workpiece 1

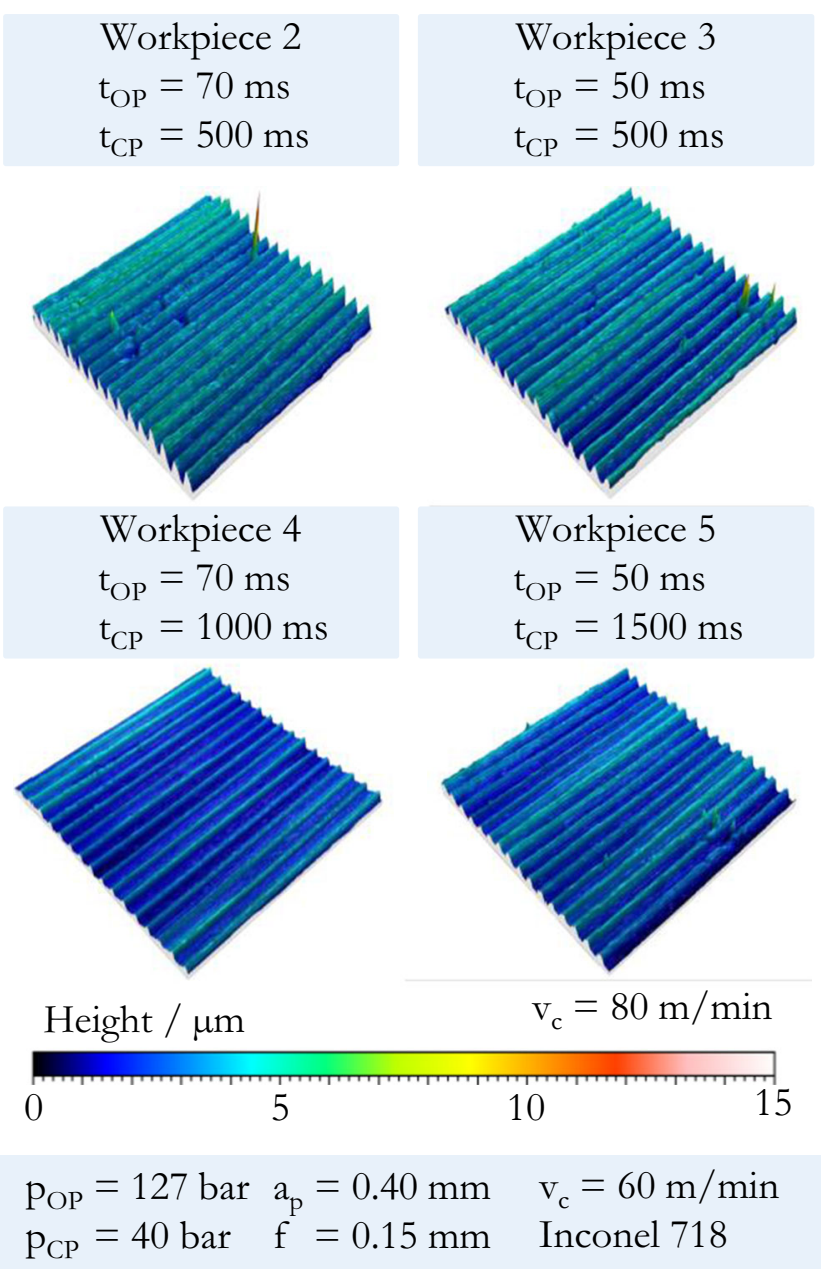

Fig. 17 Topographic 3-dimensional views

In contrast, the maximum height $\mathrm{Sz}$ and maximum peak height Sp showed a significant reduction due to the

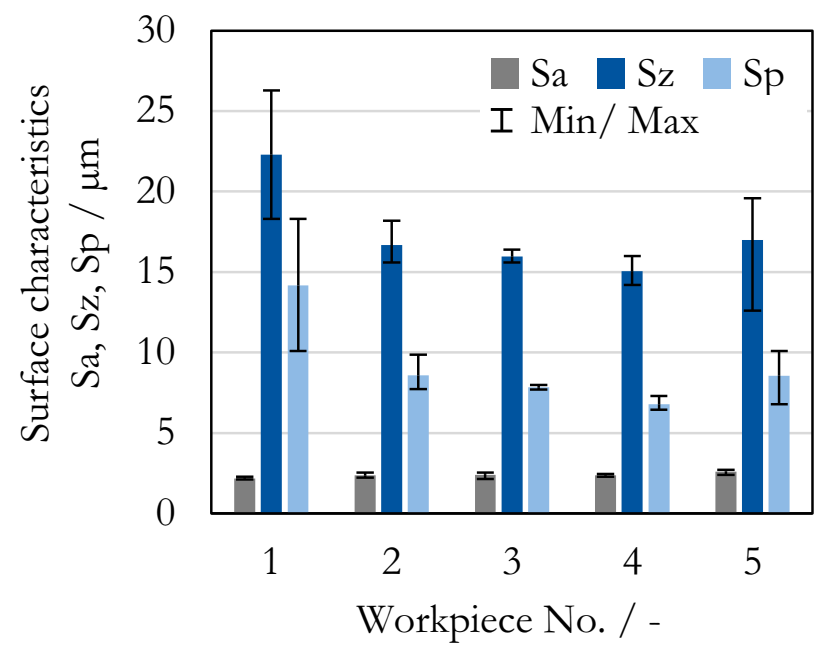

$$
\begin{array}{lll}
\mathrm{p}_{\mathrm{OP}}=127 \mathrm{bar} & \mathrm{a}_{\mathrm{p}}=0.40 \mathrm{~mm} & \text { Varied Para- } \\
\mathrm{p}_{\mathrm{CP}}=40 \mathrm{bar} & \mathrm{f}=0.15 \mathrm{~mm} & \text { meters (Fig. 5) }
\end{array}
$$

Fig. 18 Surface characteristics $\mathrm{Sa}, \mathrm{Sz}$, and $\mathrm{Sp}$ 
application of the pulsating CF supply compared to workpiece 1 which was machined with a continuous HP CF supply. Furthermore, the range of values between the different measuring points was decreased. Due to the high cutting speed $v_{\mathrm{c}}$ $=80 \mathrm{~m} / \mathrm{min}$, which was applied when machining workpiece 5 , the range of values increased compared to the other workpieces machined with pulsating CF supply.

As described in Section 4.2, the duration and frequency of the time interval 'open' $t_{\mathrm{OP}}$ is decisive for the formation of short chips that may collide with the surface. When machining workpiece 3 , only a minimal duration of the high-pressure phase 'open' $t_{\mathrm{OP}}=50 \mathrm{~ms}$ remained after the desired initial chip breakage took place. During this time, additional small chips may be broken before the phase 'closed' $t_{\mathrm{CP}}$ begins again. The long duration of the time $t_{\mathrm{CP}}=1500 \mathrm{~ms}$ reduced the number of critical chips formed during the machining of workpiece 4 , since the high-pressure phase occurred only onethird as often as during the machining of workpieces 2 and 3 . Due to the maximum investigated the duration of the time interval 'closed' $t_{\mathrm{CP}}=1500 \mathrm{~ms}$ in combination with the short time interval $t_{\mathrm{OP}}=50 \mathrm{~ms}$, these two effects were merged when machining workpiece 5 .

The increased cutting speed $v_{\mathrm{c}}$ additionally reduces the total machining time. However, as the cutting speed increases, the covered path length due to primary motion $l_{\mathrm{c}}$ in a certain time also grows. Consequently, the number of undesirable short chips produced during the time interval 'open' $t_{\mathrm{OP}}$ increases again.

During the case study, the production of a workpiece with continuous supply at $p_{\mathrm{CF}}=p_{\mathrm{CP}}=40$ bar resulted in an accumulation of chips in the machine working area, which could no longer be evacuated by the chip conveyor. Despite the increasing tool wear during the production of each workpiece with pulsating CF supply, there was never any restriction of chip removal. Further investigations have shown that the achieved tool lifetimes are comparable to the application of the HP CF supply [26]. The energy consumption of the HP unit is decreased due to the reduced pressure in contrast to the HP CF supply. Additionally, only a small investment for a valve unit is required for the application of the pulsating CF supply technology. The pulsating CF supply thus has the potential to become an ecologically, economically, and technologically sensible alternative to HP CF supply.

\section{Conclusions}

In this paper, the pulsating HP CF supply was investigated, concerning the prediction of chip length, the distribution of chip length and the finished workpiece surface. The following key findings have been identified:

Due to the pulsating CF supply, it is possible to adjust the chip length specifically. The resulting length can be described by a regression model.

The pulsating CF supply leads to a reliable chip breakage. Up to $w=77 \%$ of the chips have a length of at least $l_{\mathrm{s}}=40$ $\mathrm{mm}$. This allows to prevent damage to the workpiece surface.

An enlarged low-pressure time interval 'closed' and a reduced time interval 'open' cause an increase of the share of chips with a length $l_{\mathrm{s}} \geq 40 \mathrm{~mm}$ and a decreased frequency of the occurrence of small critical chips. Consequently, chip collisions with the front surface and therefore surface damages are reduced. Surface damage caused by the impact of a chip can include both material adhesions and pullouts.

By the use of optimized pulsating CF supply parameters, damages to the front surface caused by chip collision can be minimized. Based on the results, the pulsating CF supply has the potential to become a sensible alternative to HP CF supply.

Nomenclatures $a_{\mathrm{p}}$, Depth of cut; $A$, Cross-section of undeformed chip; $D$, Cutting fluid outlet diameter; $f$, Feed; $l_{\mathrm{s}}$, Length of curled chip; $l_{\mathrm{c}}$, Path length due to primary motion; $t_{\mathrm{CP}}$, Length of low-pressure time interval 'closed'; $t_{\mathrm{OP}}$, Length of high-pressure time interval 'open'; $p_{\mathrm{CF}}, \mathrm{CF}$ supply pressure (continuous supply); $p_{\mathrm{CP}}, \mathrm{CF}$ supply pressure during time interval 'closed'; $p_{\mathrm{OP}}, \mathrm{CF}$ supply pressure during time interval 'open'; $Q_{\mathrm{OP}}, \mathrm{CF}$ flow rate during time interval 'open'; $Q_{\mathrm{CP}}, \mathrm{CF}$ flow rate during time interval 'closed'; $v_{\mathrm{c}}$, Cutting speed; $w$, Weight proportion

Funding Open Access funding enabled and organized by Projekt DEAL. The IGF-research project 19962 N ('PulsKühl') of the German Machine Tool Builder's Association (VDW) is funded by the AiF within the program to promote joint industrial research (IGF) by the Federal Ministry for Economic Affairs and Energy, following a decision of the German Bundestag. Parts of this work can also be found in the related project report [26].

Data Availability Not applicable

Code availability Not applicable

\section{Declarations}

Conflict of interest The authors declare no competing interests.

Open Access This article is licensed under a Creative Commons Attribution 4.0 International License, which permits use, sharing, adaptation, distribution and reproduction in any medium or format, as long as you give appropriate credit to the original author(s) and the source, provide a link to the Creative Commons licence, and indicate if changes were made. The images or other third party material in this article are included in the article's Creative Commons licence, unless indicated otherwise in a credit line to the material. If material is not included in the article's Creative Commons licence and your intended use is not permitted by statutory regulation or exceeds the permitted use, you will need to obtain permission directly from the copyright holder. To view a copy of this licence, visit http://creativecommons.org/licenses/by/4.0/. 


\section{References}

1. Dudzinski D (2004) A review of developments towards dry and high speed machining of Inconel 718 alloy. Int J Mach Tools Manuf 44(4):439-456

2. Choudhury IA, El-Baradie MA (1998) Machinability of nickelbase super alloys: a general review. J Mater Process Technol 77(1-3):278-284

3. Rahman M, Seah WKH, Teo TT (1997) The machinability of Inconel 718. J Mater Process Technol 63(1-3):199-204

4. Ezugwu EO, Bonney J (2004) Effect of high-pressure coolant supply when machining nickel-base, Inconel 718, alloy with coated carbide tools. J Mater Process Technol 153-154:1045-1050

5. Denkena B, Tönshoff HKT (2011) Spanen. Grundlagen, Springer Fachmedien, Wiebaden

6. Cayli T (2015) Hochdruck-KSS-Zufuhr steigert die Produktivität und Prozesssicherheit. VDW Branchen Report 2:27-28

7. Sangermann H (2013) Hochdruck-Kühlschmierstoff-zufuhr in der Zerspanung. Apprimus-Verlag, Aachen

8. Crafoord R, Kaminski J, Lagerberg S, Ljungkrona O, Wretland A (1999) Chip control in tube turning using a high-pressure water jet. Proc Inst Mech Eng B J Eng Manuf 213(8):761-767

9. Machado AR, Wallbank J (1994) The effects of a high-pressure coolant jet on machining. Proc Inst Mech Eng B J Eng Manuf 208:29-38

10. Haberbosch R (2015) Einsatz der Hochdruck KSS-Zufuhr bei der Drehbearbeitung von Komplexen Werkstoffen in der Luftfahrt, 4. Aachener Kühlschmierstoff-Tagung, Apprimus Verlag, Aachen

11. Cayli T (2018) Surface anomalies in turning of difficult-to cut materials with high-pressure coolant supply. Apprimus-Verlag, Aachen

12. National Transportation Safety Board: Aircraft Accident Report Uncontained Engine Failure Delta Air Lines Flight 1288, (1998)

13. Klocke F (2018) Fertigungsverfahren 1 - Zerspanung mit geometrisch bestimmter Schneide. Springer Vieweg, Berlin

14. Bergs T, Splettstoesser A, Schraknepper D (2019) Pulsating highpressure cutting fluid supply for chip control in finish turning of Inconel 718. MM Sci J 12(4):3200-3205

15. Pigott RJS, Colwell AT (1952) Hi-jet system for increasing tool life, SAE Technical Paper Series, Warrendale, PA, United States

16. Ezugwu EO, Bonney J (2005) Finish machining of nickel-base Inconel 718 alloy with coated carbide tool under conventional and high-pressure coolant supplies. Tribol Trans 48(1):76-81

17. Sharman ARC, Hughes JI, Ridgway K (2008) Surface integrity and tool life when turning Inconel 718 using ultra-high pressure and flood coolant systems. Proc Inst Mech Eng B J Eng Manuf 222(6):653-664
18. Courbon C, Kramar D, Krajnik P, Pusavec F, Rech J, Kopac J (2009) Investigation of machining performance in high-pressure jet assisted turning of Inconel 718. An experimental study. Int J Mach Tools Manuf 49(14):1114-1125

19. Klocke F, Sangermann H, Krämer A, Lung D (2011) Influence of a high-pressure lubricoolant supply on thermo-mechanical tool load and tool wear behaviour in the turning of aerospace materials. Proc Inst Mech Eng B J Eng Manuf 225(1):52-61

20. Polvorosa R, Suárez A, de Lacalle LL, Cerrillo I, Wretland A, Veiga F (2017) Tool wear on nickel alloys with different coolant pressures: comparison of Alloy 718 and Waspaloy. J Manuf Process 26:44-56

21. D'Addona DM, Raykar SJ (2019) Thermal modeling of tool temperature distribution during high pressure coolant assisted turning of Inconel 718. Materials 12(3):408

22. Cica D, Kramar D (2019) Multi-objective optimization of highpressure jet-assisted turning of Inconel 718. Int J Adv Manuf Technol 105(11):4731-4745

23. Khochtali H, Ayed Y, Zemzemi F, Bensalem W (2021) Tool wear characteristics in rough turning of Inconel 718 with coated carbide tool under conventional and high-pressure coolant supplies. Int $\mathrm{J}$ Adv Manuf Technol

24. Rasch FO, Vigeland T, Bjørke Ø (1981) Hydraulic Chipbreaking. CIRP Ann 30(1):333-335

25. Bergs T, Splettstoesser A, Schraknepper D (2019) Pulsierende KSS-Zufuhr unter erhöhten Drücken beim Schlichtdrehen Schwer Zerspanbarer Werkstoffe, 6. Aachener Kühlschmierstoff-Tagung, Apprimus Verlag, Aachen

26. Splettstoesser A, Schraknepper D, Bergs T (2020) Pulsierende Zuführung des Kühlschmierstoffes bei der Drehbearbeitung von schwer zerspanbaren Materialien unter erhöhten Drücken PulsKühl. Schlussbericht, TIB Hannover

27. Sterle L, Grguraš D, Kern M, Pušavec F (2019) Sustainability assessment of advanced machining technologies, Strojniški vestnik. J Mech Eng 65(11-12):671-679

28. Metalcor GmbH, Data Sheet 2.4668 Alloy 718, Checked: March 2020.

29. Special Metals: INCONEL® Alloy 718, Checked: March 2020

30. DIN EN ISO 25178-1, Geometrical product specifications (GPS) surface texture: Areal, (2012)

31. Liu C, Wan M, Zhang W, Yang Y (2021) Chip formation mechanism of Inconel 718: a review of models and approaches. Chin J Mech Eng 34(1):34

Publisher's note Springer Nature remains neutral with regard to jurisdictional claims in published maps and institutional affiliations. 